\title{
Three-dimensional computed tomography evaluation of airway changes after treatment with Carriere Motion 3D Class II appliance
}

\author{
Khaled Hazem Attia,' Mai Hamdy Aboulfotouh, ${ }^{2}$ Ahmed Sherien Fouda ${ }^{3}$ \\ 'Professor, Department of Orthodontics and Dentofacial Orthopedics, Faculty of Dentistry, Cairo University, Egypt \\ 2Lecturer, Department of Orthodontics and Dentofacial Orthopedics, Faculty of Dentistry, Cairo University, Egypt \\ ${ }^{3}$ Teacher assistant, Department of Orthodontics and Dentofacial Orthopedics, Faculty of Dentistry, Cairo University, Egypt
}

Correspondence: Professor Khaled Hazem Attia, BDS, MSc, PhD. Professor, Department of Orthodontics and Dentofacial Orthopedics, Faculty of Dentistry, Cairo University, Cairo, Egypt. Email khaledhattia@dentistry.cu.edu.eg

Received: January 09, 2019 | Published: February 12, 2019

Copyright@ 2019 Attia et al. This is an open access article distributed under the terms of the Creative Commons Attribution License, which permits unrestricted use, distribution, and reproduction in any medium, provided the original author and source are credited.

\begin{abstract}
Background: the authors evaluated the effect of the Carriere motion II appliance on the pharyngeal airway parameters in a sample of class II patients, using cone beam computed tomography (CBCT).

Materials \& methods: A retrospective sample of 20 adult patients with class II malocclusion who received treatment with Carriere motion II appliance were included in this study. The total airway volume and the minimum cross-sectional area were assessed before and after treatment using Anatomage software on the CBCT scans. Statistical analysis of the collected data was performed.
\end{abstract}

Results: The measured airway parameters increased significantly after correction of the class II malocclusion using the Carrier motion II appliance.

Conclusion: The use of the Carriere class II motion appliance resulted in an increase the total pharyngeal airway volume as well as in the minimum crosssectional area after treatment.

\section{Introduction}

Class II malocclusion is one of the most frequent treatment challenges facing orthodontists. ${ }^{1}$ Distalization of the maxillary dentition has become one of the most popular treatment modalities for Class II and Class I malocclusion with bimaxillarydento-alveolar protrusion patients, especially when extraction treatment is not accepted by patients.,

Recently, airway analysis and the effect of different treatment modalities on the airway space have gained increased attentiveness from researchers and have had contradictory results in the literature. There are a variety of published studies on the relationship between airway anatomy and the presence as well as the severity of malocclusions. ${ }^{3-8}$ Literature reviews showed a particular association between both Class II malocclusion and vertical growth problems ${ }^{9-12}$ and the presence of constricted airways.

Previous studies also suggest that reduced airway dimensions are correlated to increases in the mandibular plane angle and that this may contribute to differences in mandibular size, position and rotation. ${ }^{13-14}$ Several studies showed a decrease in the pharyngeal airway size with extraction treatment. ${ }^{15-17}$ Guilleminault et al. ${ }^{18}$ suggested that extraction treatment may predispose to obstructive sleep apnea. On the other hand, Larsen et al. ${ }^{19}$ demonstrated strong evidence that there was no relationship between premolar extraction treatment and obstructive sleep apnea.
In 2004 a new appliance was introduced by Luis Carrière carrying his name, called the Carrière Motion appliance. ${ }^{20}$ This appliance is designed to change a class II molar relation into a class I relation by distalizing the whole posterior segment from the canine to the first molar before brackets or any other appliances are placed. The ball and socket joint built in the posterior pad has built-in stops to prevent unwanted molar tipping during distalization.

However, the effect of distalization of the maxillary dentition in nonextraction Class II patients on the airway has not been evaluated. Therefore, the purposes of this study were to evaluate to what extent does treatment to correct Angle Class II malocclusions with Carriere Motion II appliance influence the airway space.

\section{Materials and Methods}

This study is a retrospective study were patients data were recruited from the Outpatient Clinic at the Department of Orthodontics, Faculty of Dentistry, Cairo University. 20 cases treated with Carriere motion II were selected with the following inclusion criteria:

1. Post-pubertal patients with age range from 14-30 years, manifesting features of post-pubertal cervical vertebrae maturational stages 4, 5 and 6 (deceleration, maturation, and completion).

2. Class II Division 1 malocclusion with at least an end-on Class II molar relationship bilaterally.
Submit your Article | www.ologypress.com/submit-article OP, Ology $f$ in $y$ titid 
3. Well-aligned posterior maxillary segments from the canine to maxillary second molar.

4. Full permanent dentition including the second maxillary and mandibular permanent molars.

5. No sex predilection.

6. No previous orthodontic treatment.

7. Noprevious history of airway problems.

\section{Clinical Procedure}

The Carrière Motion appliance was bonded on the permanent maxillary canine and first molar and the correct size was chosen according to the manufacturer's instructions. An alginate impression was then taken for the lower arch. A cast was then poured into hard stone. A hard vacuum sheet of $1.5 \mathrm{~mm}$ in thickness was used to fabricate the Essix retainer. The posterior end of the buccal surface of the Essix appliance was trimmed opposite to the lower second molar region creating a window to expose the tube for attachment of the intraoral elastics. The appliance was then checked for retention inside the patient's mouth.

Class II elastics were attached from the maxillary canine to the mandibular second molar bilaterally. During the first month, 1/4 heavy elastics were used. The following months 3/16 heavy elastics were used. The patients were instructed to wear the elastics twentyfour hours daily except during mealtime and to change them daily.

\section{CBCT Imaging}

CBCT scans were taken before the start of treatment and after completion of distalization. The CBCT images were acquired using a Next Generation i-CAT scanner. The machine is supplied with Amorphous Silicon Flat Panel Sensor with Cesium Iodide (CsI) scintillator, $0.5 \mathrm{~mm}$ focal spot size, 14 Bit grayscale resolution, and operating at the following protocol for all the scans of the study: Tube voltage: $120 \mathrm{kVp}$, Milliampere: $18.54 \mathrm{mAs}$, Voxel size: $0.3 \mathrm{~mm}$, Scanning time: 8.9 seconds, Field of view: $17 \mathrm{~cm}$ Height $* 23 \mathrm{~cm}$ Diameter.

\section{Software analysis for assessment of airway}

Digital image files of the patients were exported in digital imaging and communications in medicine (DICOM) format and processed using the Tx Studio software (Anatomage, version 5.2, San Jose, CA)

All acquired images were converted into volumetric images and reconstructed sagittal, axial and coronal slices. The clinician needs to outline the identified airway volume of interest using a computer mouse. Once the airway volume has been selected based on the superior and inferior borders, the software program will automatically calculate the total airway volume, as well as the minimum crosssectional area, which is the most constricted part of the pharyngeal airway using color-coded constriction values. This method of measuring airway volume is considered consistent and stable, as cervical vertebrae were used as anatomic reference landmarks (Figure $1 \&$ Figure 2).

\section{Statistical analysis}

The paired t-test was used to evaluate changes in total airway volume and minimal cross-sectional area before and after Carriere Motion appliance treatment. Data are presented as mean \pm standard error. $\mathrm{P}$ values less than 0.05 were considered statistically significant.
Statistical analysis was performed using GraphPad Prism 6.0 software (GraphPad, La Jolla, CA).

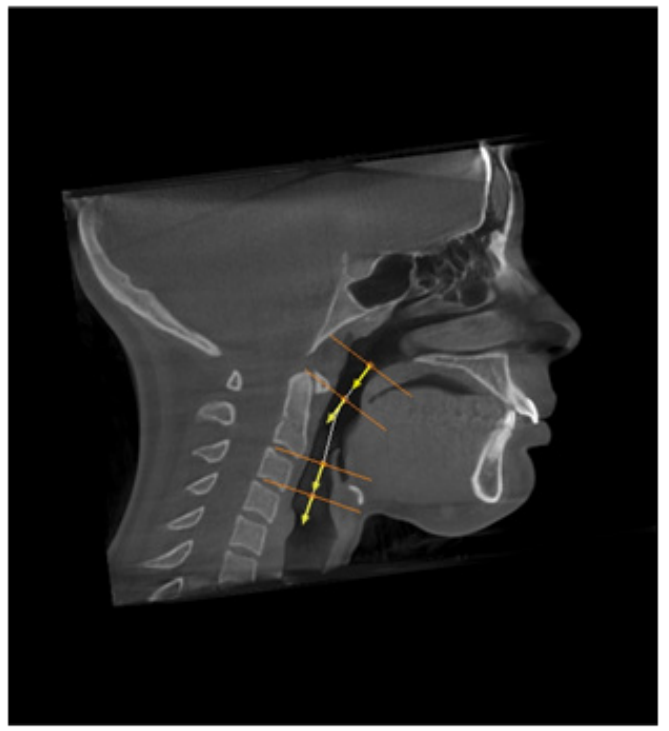

Figure I Showing outline identifying airway volume of interest

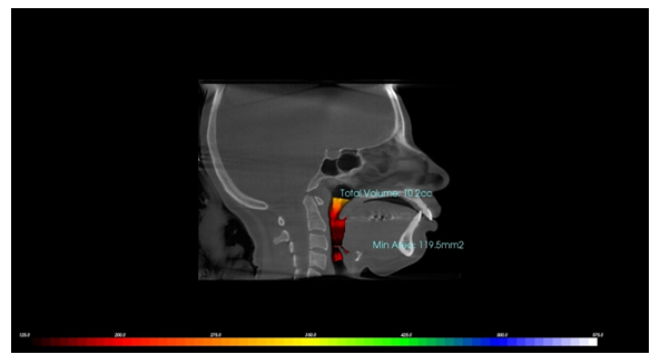

Figure 2 Airway volume before treatment with Carriere motion II appliance Volumetric assessment of patient's airway using sagittal cone beam computed tomography image and Anatomage's Tx Studio software.

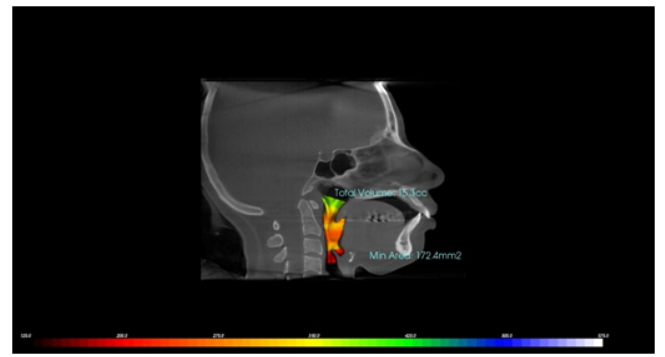

Figure 3 Airway volume after treatment with Carriere motion II appliance. Volumetric assessment of patient's airway using sagittal cone beam computed tomography image and Anatomage's Tx Studio software.

\section{Results}

\section{Total airway volume}

$P$ value and statistical significance: The statistical analysis reveals that there was an increase in the total airway volume after treatment with Carriere Motion II appliance from $11.31 \mathrm{ml}$ to $15.2 \mathrm{ml}$ (Table 1).

The two-tailed P value was less than 0.001 . By conventional criteria, this difference is considered to be statistically significant. 
Confidence interval: The mean of Group One minus Group Two equals -4.900

95\% confidence interval of this difference: From -5.548 to -4.252

Intermediate values used in calculations:

$\mathrm{t}=15.8321$

$\mathrm{df}=19$

Standard error of difference $=0.309$

Table I Comparison between total airway volume parameters before and after treatment (paired t-test).

\begin{tabular}{lll}
\hline & Pre-treatment & Post-treatment \\
\hline Mean & 11.31 & 15.2 \\
SD & 3.027 & 3.032 \\
SEM & 0.677 & 0.678 \\
$N$ & 20 & 20 \\
PValue & $<0.00 \mathrm{I}$ & \\
\hline
\end{tabular}

\section{Minimum cross-sectional area}

$P$ value and statistical significance: The statistical analysis reveals that there was an increase in the minimum cross-sectional area after treatment with Carriere Motion II appliance from $171.68 \mathrm{~mm}^{2}$ to $212.78 \mathrm{~mm}^{2}$ (Table 2).

Table 2 Comparison between minimum cross-sectional area parameters before and after treatment (paired t-test).

\begin{tabular}{lll}
\hline & Pre-treatment & Post-treatment \\
\hline Mean & 171.68 & 212.78 \\
SD & 56.3 & 61.74 \\
SEM & 12.58 & 13.8 \\
$N$ & 20 & 20 \\
PValue & $<0.001$ & \\
\hline
\end{tabular}

The two-tailed P value was less than 0.001. By conventional criteria, this difference is considered to be statistically significant.

Confidence interval: The mean of Group One minus Group Two equals -41.025

$95 \%$ confidence interval of this difference: From -52.263 to -29.787

Intermediate values used in calculations:

$\mathrm{t}=7.6406$

$\mathrm{df}=19$

The standard error of difference $=5.369$

\section{Discussion}

No previous study has evaluated the changes that may occur in the airway space after distalization of the maxillary dentition. So, the aim of our study was to evaluate the changes of the Oropharyngeal airway volume and the minimum constricted area after treatment with Carriere motion II appliance.

Evaluation of the upper airway has become an important diagnostic test in several subspecialties of dentistry, ${ }^{21}$ in part because of the controversial $^{22,23}$ but the potential impact of high resistance airways contributing to abnormal growth of the nasomaxillary complex, resulting in an increased vertical facial dimension in young patients. ${ }^{24}$ Additionally, constricted airways are thought to play a potential role in the pathophysiology of obstructive sleep apnea. ${ }^{25}$

Class II malocclusion is a common clinical finding in dentofacial orthopedics. Several treatment options have been attempted to correct this Class II malocclusion, one of those options is to distalize the maxillary first molar without extraction. In 2004, the Carrière Motion appliance was introduced with the aim of distalizing the whole posterior segment from the maxillary canine to the first molar by the use of Class II intermaxillary elastics. ${ }^{20}$

The earliest attempts to correlate pharyngeal airway with different anteroposterior malocclusions was carried out by Mergen and Jacobs ${ }^{26}$, followed by Trenouth and Timms. ${ }^{27}$ Consequently, it was concluded that subjects with class II malocclusion suffered smaller nasopharyngeal areas and depths than those with normal occlusion. This was mainly attributed to the retruded mandibular position in such patients which renders them more prone to obstructive sleep apnea. Also, Kirjavainen and Kirjavainen ${ }^{10}$ reported that Class II malocclusion subjects showed narrower Oro- and hypopharyngeal space than Class I and normal occlusion subjects.

Cephalometricradiography has been traditionally used to measure the airway, particularly in sleep studies. ${ }^{28,29}$ However, the conventional radiographic cephalometry results in superimposition of all bilateral structures and provides only a sagittal view of the skull. ${ }^{29}$ To visualize and measure the true airway volume, a three-dimensional (3D) technique is required.

Cone beam computed tomography (CBCT) is an imaging modality that utilizes a cone-shaped collimated $\mathrm{x}$-ray beam instead of a fanshaped beam. ${ }^{30}$ Its accuracy and precision for airway measurement have been documented. Through CBCT, a 3D analysis of the upper airway can be achieved in an accurate and reliable manner. ${ }^{31}$ Orthodontic software programs have developed tools for airway analyses, especially for volume size measurement.

The results of this study showed a positive effect of Carriere Motion II on increasing both the total airway volume and the minimum constricted area.

For the Total airway volume, there was a significant increase from $11.31 \pm 3.02 \mathrm{ml}$ to $15.2 \pm 3.03 \mathrm{ml}$, with a percentage of $34 \%$ increase.

For the minimum constricted area there was also a significant increase from $171.68 \pm 56.68 \mathrm{~mm}^{2}$ to $212.78 \pm 61.74 \mathrm{~mm}^{2}$, with a percentage of $23.48 \%$ increase.

Recent studies explained these changes in the airway by understanding that most of the class II treatment mechanics involve the forward positioning of the mandible as the main factor in correcting the sagittal relationship. Forward positioning of the mandibular arch and teeth subsequently affects the available room for the tongue, thereby affecting the position of the hyoid bone and causing a subsequent change in the dimensions of the posterior airway.

Regarding the mechanics of the Carriere motion II appliance, class II elastics produce the effect of mandibular arch protraction which in turn repositions the tongue anteriorly increasing the airway size. 


\section{Acknowledgements}

None.

\section{Conflicts of interest}

The author declares no conflicts of interest.

\section{References}

1. Proffit WR, Fields HW Jr, Moray LJ. Prevalence of malocclusion and orthodontic treatment need in the United States. Int J Adult Orthodon Orthognath Surg. 1998;13(2):97-106.

2. Kook YA, Park JH, Kim Y, et al. Sagittal correction of adolescent patients with modified palatal anchorage plate appliances. Am J Orthod Dentofacial Orthop. 2015;148(4):674-684.

3. Kook YA, Park JH, Kim Y, et al. Orthodontic treatment of skeletal Class ii adolescent with anterior open bite using mini screws and modified palatal anchorage plate. J Clin Pediatr Dent. 2015;39(2):187-192.

4. Aboudara C, Nielsen I, Huang JC, et al. Comparison of airway space with conventional lateral headfilms and 3-dimensional reconstruction from cone-beam computed tomography. Am J Orthod Dentofacial Orthop. 2009;135(4):468-479.

5. Aboudara CA, Hatcher D, Nielsen IL, et al. A three-dimensional evaluation of the upper airway in adolescents. Orthod Craniofac Res. 2003;6:173-175.

6. Abramson Z, Susarla S, August M et al. Three-dimensional computed tomographic analysis of airway anatomy in patients with obstructive sleep apnea. J Oral Maxillofac Surg. 2010;68:354-362.

7. Abramson Z, Susarla S, Troulis M, et al. Age-related changes of the upper airway assessed by 3-dimensional computed tomography. J Craniofac Surg. 2009;20(Suppl 1):657-663.

8. Akcam MO, Toygar TU, Wada T. Longitudinal investigation of the sof palate and nasopharyngeal airway relations in different rotation types. Angle Orthod. 2002;72(6):521-526.

9. Joseph AA, Elbaum J, Cisneros GJ, et al. A cephalometric comparative study of the soft tissue airway dimensions in persons with hyperdivergent and normodivergent facial patterns. J Oral Maxillofac Surg. 1998; 56(2):135-139.

10. Kirjavainen M, Kirjavainen T. Upper airway dimensions in Class II malocclusion. Effects of headgear treatment. Angle Orthod. 2007;77(6):1046-1053.

11. Mohsenin V. Effects of gender on upper airway collapsibility and severity of obstructive sleep apnea. Sleep Med. 2003;4(6):523-529.

12. Stellzig-Eisenhauer A. The influence of cephalometric parameters on the resonance of speech in cleft lip and palate patients. An interdisciplinary study 2001; J Orofac Orthop. 62(3):202-223.

13. Joseph AA, Elbaum J, Cisneros GJ, et al. A cephalometric comparative study of the soft tissue airway dimensions in persons with hyperdivergent and normodivergent facial patterns. J Oral Maxillofac Surg 1998; 56(2):135-139.

14. Ucar FI, Uysal T. Orofacial airway dimensions in subjects with Class I malocclusion and different growth patterns 2011; Angle Orthod 81(3):460-468.
15. Wang Q, Jia P, Anderson NK, et al. Changes of pharyngeal airway size and hyoid bone position following orthodontic treatment of Class I bimaxillary protrusion. Angle Orthod. 2012;82(1):115-121.

16. Chen Y, Hong L, Wang CL, et al. Effect of large incisor retraction on upper airway morphology in adult bimaxillary protrusion patients. Angle Orthod. 2012;82(6):964-970.

17. Germec-Cakan D, Taner T, Akan S. Uvulo-glossopharyngeal dimensions in non-extraction, extraction with minimum anchorage, and extraction with maximum anchorage. Eur J Orthod. 2011;33(5):515-520.

18. Guilleminault C, Abad VC, Chiu HY, et al. Missing teeth and pediatric obstructive sleep apnea. Sleep Breath. 2016;20(2):561-568.

19. Larsen AJ, Rindal DB, Hatch JP, et al. Evidence supports no relationship between obstructive sleep apnea and premolar extraction: an electronic health records review. J Clin Sleep Med. 2015;11(12):14431448.

20. Carrière L. A new Class II distalizer. J Clin Orthod. 2004;38(4):224-231.

21. Tso HH, Lee JS, Huang JC, et al. Evaluation of the human airway using cone-beam computerized tomography. Oral Surg Oral Med Oral Pathol Oral Radiol Endod. 2009;108(5):768-776.

22. Vig PS. Nasal obstruction and facial growth: the strength of evidencefor clinical assumptions. Am J Orthod Dentofacial Orthop. 1998;113(6):603-611.

23. Lenza MG, De Lenza MM, Dalstra M, et al. An analysis of different approaches to the assessment of upper airway morphology: a CBCT study. Orthod Craniofac Res. 2010;13(2):96-105.

24. Subtelny JD. The significance of adenoid tissue in orthodontia. Angle Orthod. 1954;24(2):59-69.

25. Johal A, Patel SI, Battagel JM. The relationship between craniofacial anatomy and obstructive sleep apnea: a case-controlled study. J Sleep Res 2007;16(3):319-326.

26. Mergen D, Jacobs RM. The size of nasopharynx-associated with normal occlusion and Class II malocclusion. Angle Orthod. 1997;40(4):342 346.

27. Trenouth M, Timms D. Relationship of the functional oropharynx to craniofacial morphology. Angle Orthod. 1999;69(5):419-423.

28. Albajalan OB, Samsudin AR, Hassan R. Craniofacial morphology of Malay patients with obstructive sleep apnoea Eur J Orthod. 2011;33(5):509-514.

29. Tangugsorn V, Skatvedt O, Krogstad O, et al. Obstructive sleep apnea: a cephalometric study. Part I. Cervico-craniofacial skeletal morphology. Eur J Orthod. 1995;17(1):45-56.

30. Farman A, Scarfe W. The basics of maxillofacial cone beam computed tomography. Semin Orthod, 2009;15(1):2-13.

31. Guijarro-Martínez R, Swennen GR. Cone-beam computerized tomography imaging and analysis of the upper airway: a systematic review of the literature. Int J Oral Maxillofac Surg. 2011;40(11):12271237. 